\title{
CERTIFICADO DE IDONEIDAD Y CONSENTIMIENTO \\ DE LA ENTIDAD PÚBLICA ESPAÑOLA. A PROPÓSITO DE LA DENEGACIÓN DE INSCRIPCIÓN EN EL REGISTRO CIVIL DE UNA ADOPCIÓN CONSTITUIDA EN PORTUGAL [RDGRN (2a) DE 3 DE OCTUBRE DE 2019]
}

\author{
CERTIFICATE OF SUITABILITY AND CONSENT FROM \\ THE SPANISH PUBLIC ENTITY. REGARDING THE DENIAL \\ OF REGISTRATION IN THE CIVIL REGISTRY OF AN \\ ADOPTION CONSTITUTED IN PORTUGAL [RDGRN $\left(2^{\mathrm{ND}}\right)$ \\ OF OCTOBER 3, 2019]
}

\author{
Antonia Durán Ayago \\ Profesora Titular de Derecho Internacional Privado \\ Universidad de Salamanca
}

Recibido: 19.05.2021 / Aceptado: 10.05.2021

DOI: https://doi.org/10.20318/cdt.2021.6287

\begin{abstract}
Resumen: Se deniega la inscripción en el Registro Civil español de una adopción constituida en Portugal por considerar no cumplidos los apartados tercero y cuarto del artículo 26 de la Ley de adopción internacional, esto es, por no aportar certificado de idoneidad emitido por la entidad pública competente española y faltar el consentimiento de la entidad pública correspondiente al último lugar de residencia en España de la niña adoptada que ostentaba la nacionalidad española.
\end{abstract}

Palabras clave: Adopción internacional, certificado de idoneidad, inscripción registral

Abstract: The registration in the Spanish Civil Registry of an adoption constituted in Portugal is denied for considering the third and fourth sections of article 26 of the International Adoption Law not complied with, that is, for not providing a certificate of suitability issued by the competent Spanish public entity and missing the consent of the public entity corresponding to the last place of residence in Spain of the adopted minor who held Spanish nationality.

Keywords: International adoption, certificate of suitability, registration.

Sumario: I. A modo de introducción II. Los hechos III. Cuestiones jurídicas 1. ¿Adopción transfronteriza o internacional? 2. Certificado de idoneidad de entidad pública competente española cuando adoptante sea español y resida en España 3. Consentimiento de la entidad pública competente española cuando el adoptando sea español IV. Conclusiones. 


\section{A modo de introducción}

1. Cuando una adopción se constituye ante autoridad extranjera y debe acceder al Registro Civil español porque adoptante $u$ adoptado sea español, habrá que estar siempre a un procedimiento de reconocimiento incidental registral en el que se controlarán los requisitos exigidos en los apartados segundo, tercero y cuarto del artículo 26 de la Ley 54/2007, de 28 de diciembre, de adopción internacional ${ }^{1}$ (en adelante, LAI), con independencia de que su reconocimiento pueda quedar amparado en el ámbito convencional, si fuera el caso².

En concreto, es preciso que la adopción que pretende acceder al Registro Civil tenga efectos equivalentes a la adopción en España, esto es, se trate de una adopción plena e irrevocable, siempre que el adoptante o adoptado sea español; se haya emitido con carácter previo a la constitución de la adopción el certificado de idoneidad del adoptante por la entidad pública competente española, si este es español y reside en España y si el adoptando fuera español, la entidad pública española correspondiente al último domicilio en España del adoptando, debe haber consentido en la adopción ${ }^{3}$.

2. En la Resolución de la Dirección General de los Registros y del Notariado (en adelante, DGRN) que comentamos ${ }^{4}$, se pretendía inscribir en el Registro Civil español una adopción constituida ante autoridad judicial portuguesa. No se aportan ni el certificado de idoneidad emitido por la entidad pública española competente respecto de los adoptantes, ni el consentimiento de la entidad pública correspondiente a la última residencia en España de la niña adoptada que tiene la nacionalidad española. En consecuencia, se deniega la inscripción. Como intentaré demostrar en este breve comentario la respuesta dada a este caso es cuestionable.

\section{Los hechos}

3. Los interesados, un matrimonio formado por un español y una ciudadana portuguesa, solicitaron la inscripción de la adopción constituida en Portugal de una menor nacida en España en 2011, hija de padre portugués y madre española, cuya inscripción de nacimiento constaba practicada en el Registro Civil de Palma de Mallorca. El Encargado del Registro denegó la inscripción porque no se había aportado ni el certificado de idoneidad ni el consentimiento de la entidad pública española a los que se refieren los apartados tres ${ }^{5}$ y cuatro ${ }^{6}$ del artículo 26 LAI.

\footnotetext{
BOE núm. 312, de 29 de diciembre de 2007.

2 Así se exige por la Disposición adicional segunda de la Ley Orgánica 1/1996, de 15 de enero, de protección jurídica del menor: "Para la inscripción en el Registro español de las adopciones constituidas en el extranjero, el encargado del Registro apreciará la concurrencia de los requisitos del artículo 9.5 del Código Civil.". A su vez, el artículo 9.5 CC. remite a la Ley de adopción internacional: "La adopción internacional se regirá por las normas contenidas en la Ley de Adopción Internacional. Igualmente, las adopciones constituidas por autoridades extranjeras surtirán efectos en España con arreglo a las disposiciones de la citada Ley de Adopción Internacional". Vid. A. L. Calvo Caravaca / J. Carrascosa González, Tratado de Derecho Internacional Privado, tomo II, Tirant lo Blanch, 2020, pp. 1965 y ss.

3 S. Álvarez GonzÁlez, "Reconocimiento e inscripción en el registro civil de las adopciones internacionales", Revista Española de Derecho Internacional, 2006-2, pp. 683-710; M. D. ORTIZ VIDAL, La adopción internacional tras la Ley 26/2015, Tirant lo Blanch, 2020, pp. 218-219.

${ }^{4}$ BIMJ, año LXXIV, octubre 2020, núm. 2.234, pp. 18-21. Esta resolución también ha sido comentada por J. CARRASCOSA GonZÁLEZ, “Adopción constituida en Portugal y certificado de idoneidad del adoptante: el interés del menor y la residencia del adoptante. Reflexiones primaverales en torno a la RDGRN [2a] 3 octubre 2019 [adopción constituida en Portugal]", accesible en Adopción constituida en Portugal y certificado de idoneidad del adoptante: el interés del menor y la residencia del adoptante. Reflexiones pre-primaverales en torno a la RDGRN [2a 3 octubre 2019 [adopción constituida en Portugal] | (accursio.com), consultado el 23 de marzo de 2021.

5 "3. Cuando el adoptante sea español y residente en España, la Entidad Pública española competente deberá declarar su idoneidad previamente a la constitución de la adopción por el órgano competente extranjero. No se exigirá dicha declaración de idoneidad en los casos en los que de haberse constituido la adopción en España no se hubiera requerido la misma.".

6 "4. Si el adoptando fuera español en el momento de constitución de la adopción ante la autoridad extranjera competente, será necesario el consentimiento de la Entidad Pública correspondiente a la última residencia del adoptando en España.".
} 
La solicitud realizada se basaba en una sentencia de un órgano judicial portugués de 25 de julio de 2014, cuya validez y efectos homologables a la adopción española no se cuestionaron, pero tanto el Encargado del Registro como la DGRN consideran que no es posible su inscripción mientras no se aporten también el certificado de idoneidad de los adoptantes y el consentimiento de la entidad pública española correspondiente, entendiendo que se dan los requisitos espaciales indicados en la norma para exigirlos.

4. En relación con el certificado de idoneidad de los adoptantes emitido por la entidad pública española competente, se exige siempre que el adoptante sea español y resida en España. La cuestión controvertida en este caso gira en torno a si realmente la residencia de los adoptantes estaba en España en el momento de la constitución de la adopción, momento al que hay que estar para la exigencia de este concreto requisito, y no a la residencia que tuvieran cuando se insta la inscripción. Las dudas surgen porque el promotor presentó su solicitud a través del Registro Civil de Vigo pocos meses después de constituida la adopción, declarando que allí estaba domiciliado y aportando el certificado de empadronamiento correspondiente, en lugar de hacerlo a través del Registro consular correspondiente al domicilio en el extranjero, lo que da pie al Encargado del Registro y a la Dirección a entender que estaba domiciliado en España en el momento de la constitución de la adopción, presunción, que, como veremos, es fácilmente rebatible, no solo por el resto de documentos y declaraciones que se aportan por el interesado, sino por la propia sentencia de constitución portuguesa de la adopción.

En cuanto al consentimiento de la entidad pública española correspondiente al último lugar de residencia de la menor en España, en principio es exigible porque la menor, nacida en España en 2011 y española de origen al ostentar su madre biológica tal nacionalidad, residió en nuestro país hasta junio de 2012. La adopción se constituye en 2014. En este caso, habría que ponderar en función de las circunstancias que concurren en él, si realmente este consentimiento es tan relevante como para denegar la inscripción, o si, en su caso, sería posible obtenerlo a posteriori.

\section{Cuestiones jurídicas}

\section{1. ¿Adopción transfronteriza o internacional?}

5. Un dato no poco relevante, pero por el que pasa de puntillas la resolución, es que la constitución de la adopción se haya llevado a cabo en Portugal, ante autoridad judicial. Las implicaciones de ello no son menores, por varias cuestiones, entre ellas, y singularmente importante es que Portugal, al igual que España, es parte del Convenio de La Haya de 29 de mayo de 1993, relativo a la protección del niño y a la cooperación en materia de adopción internacional. Este Convenio, directamente, sólo se aplica cuando menor y adoptante/s tienen su residencia en Estados distintos (adopciones transfronterizas), ambos parte del Convenio, pero parece obvio que los requisitos que en él se exigen para la tramitación de la adopción, también se tendrán en cuenta en las adopciones internacionales. Entre ellos, uno que nos interesa a los efectos del presente caso es el certificado de idoneidad de los adoptantes, al que se alude en el artículo 5 a) del Convenio en relación con los artículos 15 y 17 d), en Portugal denominado certificado de selección regulado en el artículo 44 Lei $n^{\circ}$ 143/2015, de 08 de Setembro, regime jurídico do proceso de adoçao ${ }^{7}$, que, según se indica en la resolución, es aportado por los adoptantes (párrafo séptimo

7 El contenido de este precepto es el siguiente: "Preparação, avaliação e selecção 1 - Logo após a formalização da candidatura, o organismo de segurança social ou a instituição particular autorizada dá início ao conjunto de procedimentos de preparação, avaliação e seleção, o qual deve estar concluído no prazo máximo de seis meses. 2 - O conjunto de procedimentos de preparação, avaliação e seleção é composto por sessões formativas, entrevistas psicossociais e aplicação de outros instrumentos de avaliação técnica complementar, designadamente de avaliação psicológica, tendo em vista a capacitação do candidato e a emissão de parecer sobre a pretensão. 3 - A avaliação da pretensão do candidato a adotante e o correspondente parecer devem incidir, nomeadamente, sobre a personalidade, a saúde, a idoneidade para criar e educar a criança, a situação familiar e económica do candidato a adotante e as razões determinantes do pedido. 4 - Em caso de parecer desfavorável, é obrigatória a audiência dos interessados em momento prévio ao da decisão da rejeição da candidatura, nos termos previstos no Código do Procedimento Administrativo. 5 - Concluídos os procedimentos, o organismo de segurança social ou a instituição particular au- 
in fine), especificándose en el artículo 45 que tiene una vigencia de tres años, idéntica vigencia que en España, según establece el artículo 10, apartado tercero LAI. En España, por idoneidad se entiende la capacidad, aptitud y motivación adecuadas para ejercer la patria potestad, atendiendo a las necesidades de los niños adoptados, y para asumir las peculiaridades, consecuencias y responsabilidades que conlleva la adopción internacional (art. 10.1 LAI) ${ }^{8}$. En términos similares, se manifiesta el apartado tercero del artículo 44 de la Lei $n .{ }^{\circ} 143 / 2015$, de 08 de Setembro, regime jurídico do proceso de adoçao, indicando que "la valoración de la pretensión del solicitante y el dictamen correspondiente debe centrarse, entre otros, en la personalidad, la salud, la idoneidad para criar y educar al niño, la situación familiar y económica del solicitante de la adopción y los motivos determinantes de la solicitud".

6. Parece obvio que si los adoptantes aportan ese certificado de idoneidad es porque han sido evaluados convenientemente por la autoridad competente portuguesa, que los ha considerado idóneos para llevar a cabo la adopción, y es de entender también que si hay una sentencia portuguesa que ha constituido la adopción es porque los adoptantes residían en ese país en el momento de la constitución?. Con todo ello, la exigencia de aportar certificado de idoneidad emitido por la entidad pública española competente no debería exigirse, puesto que todos los indicios llevan a que en el momento de la constitución de la adopción los adoptantes y la menor residían en Portugal, por lo que no estaríamos dentro del ámbito de aplicación del artículo 26.3, al entender que, en el momento de la constitución de la adopción, la adoptante, de nacionalidad española, no tenía su residencia habitual en España. Entre otras cosas, cabe apuntar que, si los adoptantes hubieran tenido su residencia en España y la menor en Portugal, a todos los efectos se debería haber aplicado el CH 1993 y el tribunal portugués debería haber emitido el certificado al que hace referencia el artículo 23 del mismo ${ }^{10}$.

\section{Certificado de idoneidad de entidad pública competente española cuando adoptante sea español y resida en España}

7. En la Resolución-Circular de 15 de julio de 2006, de la Dirección General de los Registros y del Notariado, sobre reconocimiento e inscripción en el Registro Civil español de las adopciones internacionales ${ }^{11}$, se especifica, aludiendo al, en ese momento vigente, artículo 9.5 VI del Código Civil, que para el reconocimiento en España de la adopción constituida ante autoridad extranjera en los casos en que el adoptante es español y está domiciliado en España al tiempo de la adopción, es precisa la intervención de la Entidad pública competente española al requerir un certificado de idoneidad del adoptante

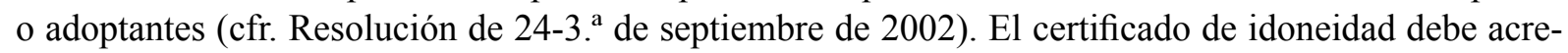

torizada profere decisão fundamentada e notifica-a ao candidato. 6 - Em caso de aceitação da candidatura, é emitido certificado de seleção, sendo os candidatos selecionados obrigatoriamente inscritos na lista nacional, nos termos do artigo $10 .{ }^{\circ} 7$ - Em caso de rejeição da candidatura, a notificação da decisão deve incluir referência à possibilidade de recurso, menção do prazo e identificação do tribunal competente para o efeito". Accesible en http://www.pgdlisboa.pt/leis/lei_mostra_articulado.php?artigo_id= 2423A0044\&nid=2423\&tabela=leis\&pagina=1\&ficha=1\&so_miolo=\&nversao=\#artigo, consultado el 15 de abril de 2021.

8 S. Adroher Biosca, "Capacidad, idoneidad y elección de los adoptantes en la adopción internacional: un reto para el ordenamiento jurídico español (I), Revista Crítica de Derecho Inmobiliario, Año LXXXIII, Mayo-Junio 2007, núm.701, pp. 950-1004.

9 En cuanto a los criterios de competencia judicial internacional, hay que tener en cuenta el artículo 62 Lei n. ${ }^{\circ} 41 / 2013$, de 26 de Junho, Código de Processo civil: “Os tribunais portugueses são internacionalmente competentes: a) Quando a ação possa ser proposta em tribunal português segundo as regras de competência territorial estabelecidas na lei portuguesa; b) Ter sido praticado em território português o facto que serve de causa de pedir na ação, ou algum dos factos que a integram; c) Quando o direito invocado não possa tornar-se efetivo senão por meio de ação proposta em território português ou se verifique para o autor dificuldade apreciável na propositura da ação no estrangeiro, desde que entre o objeto do litígio e a ordem jurídica portuguesa haja um elemento ponderoso de conexão, pessoal ou real.". Accesible en http://www.pgdlisboa.pt/leis/ lei_busca_assunto_diploma.php?buscajur=internacional\&artigo_id $=\&$ pagina $=1 \&$ ficha $=1 \&$ nid $=1959 \&$ tabela $=$ leis\&diplomas $=$ \&artigos=\&so_miolo=, consultado el 16 de abril de 2021 .

10 Vid. Resolución DGRN núm. 3/2002 de 24 septiembre (JUR 2003\15537).

11 BOE núm. 207, de 30 de agosto de 2006. 
ditar la capacidad jurídica del solicitante, siempre con arreglo a la Ley material española ${ }^{12}$. El objetivo de este requisito es evitar que personas no idóneas para ser adoptantes acudan a países que no controlan con rigor la idoneidad de los adoptantes e insten en tales países una adopción que, posteriormente, intentan que sea reconocida en España ${ }^{13}$. El que la idoneidad sea certificada de antemano pretende evitar, asimismo, un doble abandono del menor, o una retirada de la patria potestad a posteriori si se demuestra que no se ejerce debidamente ${ }^{14}$.

8. En ausencia de este requisito, la DGRN entiende que se debe denegar el reconocimiento y, en consecuencia, la inscripción en el Registro civil español ${ }^{15}$. La DGRN ha sido estricta con la exigencia de este requisito. Este rigor quedó atenuado por el reconocimiento de la posibilidad de que el certificado de idoneidad se obtuviera después de constituida la adopción en el extranjero, no siendo necesario que fuera previo ${ }^{16}$. Sin embargo, la LAI elimina este factor de flexibilidad al exigir que la declaración de idoneidad por la entidad pública española sea previa a la constitución de la adopción por la autoridad pública extranjera ${ }^{17}$. Algo en lo que al parecer no recaba la Dirección en esta resolución en la que afirma: "No obstante, este rigor queda atenuado por la posibilidad de que el certificado de idoneidad-que expide la entidad pública de la Comunidad Autónoma correspondiente a la residencia habitual de los solicitantes- se obtenga después de constituida la adopción en el extranjero" ${ }^{18}$. De ahí, quizás, que el texto de la resolución comience con un "No es inscribible, por el momento...". El problema que plantea esta norma es la de definir el grado de ineficacia que aquejaría a la adopción en caso de infracción ${ }^{19}$, que básicamente se reduciría a la no inscripción. Si bien es cierto que uno de los principales efectos que tiene la inscripción es que constituye el paso previo para la obtención de la nacionalidad española, y en este caso no sería necesario, pues la niña adoptada ostenta la nacionalidad española de origen, por ser su madre biológica española, lo cierto es, que por tratarse de un acto que afecta al estado civil de una persona que ya es española, los requisitos exigidos para la inscripción deberían haberse valorado de forma más ceñida a los hechos.

La DGRN en su Consulta de 2 de febrero de 1999, puso de relieve que "la declaración de idoneidad no es exigible cuando el adoptante español es residente en el extranjero, lo que significa que

12 Vid. Resolución DGRN núm. 3/2009, de 15 de junio de 2009 (JUR 2010\316096) y Resolución DGRN núm. 78/2014, de 3 de enero de 2014 (RJ 2014\4731).

13 Apunta P. Orejudo Prieto de los Mozos, "El certificado de idoneidad de los adoptantes en el marco de la prevención del tráfico internacional de menores (con especial referencia a las adopciones rumanas)", Aranzadi civil, núm. 12, octubre, 1998, p. 9, que "aunque el certificado no sea un «mecanismo ideado para fiscalizar si la adopción se constituye en el extranjero con las garantías adecuadas», pues es evidente que se dirige a constatar únicamente la aptitud de los futuros adoptantes, en ciertos supuestos su ausencia puede ser indicativa de la existencia de una adopción fraudulenta, o cuanto menos, irregular.". Con referencia a P. A. De Miguel AsEnsio, Eficacia de las resoluciones extranjeras de jurisdicción voluntaria, Madrid, Eurolex, 1997, p. 206. En el mismo sentido, A. L. Calvo Caravaca / J. Carrascosa González, La ley 54/2007 de 28 de diciembre de 2007 sobre adopción internacional (Reflexiones y comentarios), Comares, Granada, 2008, p. 211; M. J. SÁNCHEz CANO, "El reconocimiento incidental de una adopción internacional vinculado a la adquisición de la nacionalidad española: aspectos prácticos", Cuadernos de Derecho Transnacional (Octubre 2019), Vol. 11, núm. 2, p. 806; J. M. Díaz Fraile, "Problemas actuales de la adopción internacional", Anuario de la Facultad de Derecho de la Universidad Autónoma de Madrid, 15 (2011), p. 140, accesible en http://afduam.es/wp-content/uploads/pdf/15/J\%20M\%20Diaz.pdf, consultado el 15 de abril de 2021.

14 J. M. Espinar VicenTE, "La adopción de menores constituida en el extranjero y el reconocimiento de la patria potestad en España", Actualidad Civil, núm. 32, 1997, p. 771.

15 Vid. Resolución DGRN núm. 6/2007, de 17 septiembre (JUR 2009\8036).

${ }^{16} C f r$. Resolución 25-3. a de junio de 1999 y consulta de 23 de octubre de 2006.

17 Ya antes de la LAI, A. Borrás RodríGuez, "La regulación de la adopción en España: examen particular de la adopción internacional", Anuario de Psicología, 1996, pp. 20-21, consideraba que permitir tener en cuenta "el certificado posterior a la constitución de la adopción no favorecía el interés del menor, pues al tener que emitir un juicio a posteriori sobre la idoneidad de los adoptantes, las autoridades encargadas van a verse presionadas para decidir en un sentido positivo, toda vez que el rechazo a emitir la certificación supondría un gran perjuicio para los adoptados, que se verían de nuevo privados de una familia". Cfr. P. Orejudo Prieto de los Mozos, "El certificado de idoneidad...”, loc. cit., p. 14.

18 Alineadas con lo que marca la LAI, en cambio, las RDGRN núm. 3/2009, de 15 de junio (JUR 2010\316096), núm. 3/2013, de 12 de diciembre (JUR 2014/209423), 3 de enero de 2014 (LA LEY 69868/2014) y núm. 77/2014 de 3 enero (JUR 2014\209428).

${ }_{19}$ A juicio de J. M. Díaz Fraile, "Problemas actuales...", loc., cit., p. 140, "la sanción de la nulidad absoluta sería desproporcionada". 
ha de ser el extranjero el lugar de su residencia habitual (artículo 40 del Código Civil); sin que pueda excluirse algún caso en que sea claro el propósito del adoptante de fijar su domicilio en el extranjero, es razonable entender que la residencia habitual en el extranjero se manifiesta por ser residente legal en el pais de que se trate".

Aunque no manejamos esta hipótesis, puesto que consideramos, de la observación de los elementos aportados en el caso, que los adoptantes residían en Portugal en el momento de la constitución de la adopción, quizás convendría valorar si en casos como el presente, cuando la adopción se constituya en un Estado con estándares de exigencia equiparables al nuestro, como sucede con Portugal, no sería posible cumplir este requisito de valoración de la idoneidad del adoptante con la emisión del correspondiente certificado por parte de la entidad extranjera competente conforme al lugar de constitución de la adopción.

9. Volviendo al caso que nos ocupa, existe un certificado de selección de los adoptantes, pero las dudas se plantean para la Dirección por haber aportado el promotor el certificado de empadronamiento en España y haber presentado la solicitud de inscripción directamente en el Registro Civil de Vigo "pocos meses después de la constitución de la adopción". Precisa la resolución, que "es cierto que la prueba del certificado del padrón municipal no es exclusiva y que la residencia habitual puede acreditarse a través de cualquier otro medio admitido en Derecho, correspondiendo al encargado del Registro civil y, en su caso, a los tribunales la valoración libre de los datos que hayan sido aportados. Pero en este caso se da la circunstancia de que es el propio solicitante quien ha generado la contradicción que surge de la documentación aportada, por lo que, para poder eximirle de la necesidad de aportar el certificado de idoneidad, deberá ser también él quien presente las pruebas necesarias que acrediten de forma suficiente que su domicilio habitual y efectivo estaba fijado en Portugal en el momento de la adopción". Esto es, que se exige al promotor que aporte pruebas de que realmente residía en Portugal en el momento de la constitución de la adopción, como si no fueran pruebas suficientes el aportar el certificado de selección de las autoridades portuguesas y la sentencia de constitución de la adopción.

10. La exigencia que comentamos sólo contempla como excepción aquellas en las que no es exigible este certificado en las adopciones nacionales. Así, no es necesario obtener el certificado de idoneidad siempre que el adoptante sea el cónyuge del progenitor del adoptando [RDGRN (14 $) 11$ de febrero de 2013; 12 de junio de 2012, (6 $6^{\text {a }}$ de 12 de septiembre de 2002] o en el caso de un previo acogimiento legal del menor por los padres adoptivos durante más de un año (art. 176.2.3 $\left.{ }^{\circ} \mathrm{Cc}\right)$.

11. Ahora bien, dentro de este capítulo de excepciones no se incluye el supuesto en que el adoptante tenga otra nacionalidad extranjera, además de la española, e invoque aquella para eximirse de la exigencia del certificado de idoneidad. La DGRN en su consulta de 20 de febrero de 2007, así lo aclaró, indicando que "en nuestro sistema de Derecho Internacional Privado, a los efectos de determinar la ley aplicable en los supuestos internacionales, es decir, a las situaciones y relaciones jurídicas que presenten algún elemento de extranjería, establece una regla de preferencia o prevalencia de la nacionalidad española del que ostente además otra no prevista en nuestras leyes o Tratados internacionales, según dispone el párrafo segundo del artículo 9.9 del Código Civil"20.

\section{Consentimiento de la entidad pública competente española cuando el adoptando sea español}

12. En lo que se refiere al segundo documento omitido, el apartado cuarto del artículo 26 LAI exige un requisito complementario cuando, como en este caso, se trata de la adopción de una persona española, siendo necesario el consentimiento de la entidad pública correspondiente a la última residencia en España del adoptando. El objetivo de este requisito, de escasa aplicación práctica por ser España,

20 A. L. Calvo Caravaca / J. Carrascosa González, Tratado de Derecho Internacional Privado, op. cit., p. 1980; J. M. Díaz Fraile, "Problemas actuales...,", loc. cit., pp. 140-141. 
esencialmente, un Estado de recepción en materia de adopción, es evitar el fraude que podría darse al trasladar el domicilio o residencia del adoptando español al extranjero para evitar la necesidad de una propuesta previa por parte de la entidad pública española ${ }^{21}$. Y en este caso resulta exigible porque la menor, nacida en España en 2011 y española de origen al ostentar su madre biológica tal nacionalidad, residió en nuestro país hasta junio de 2012, según declaran los propios recurrentes. La cuestión es que, en este caso, el consentimiento de la Entidad pública española correspondiente a la última residencia de la niña en España sí podría obtenerse a posteriori, por lo que se trata de un requisito también salvable.

\section{Conclusiones}

13. La resolución que hemos comentado se inicia con un elocuente "no es inscribible, por el momento", lo que indica que realmente los motivos de rechazo de la inscripción no son contundentes. Comenzando por el más obvio, el señalado en el apartado cuarto del artículo 26 LAI, el consentimiento de la entidad pública española correspondiente al último domicilio del adoptando en España si éste es español, podría obtenerse con posterioridad a la adopción y, en consecuencia, bastaría requerirlo para que la entidad lo diera, si no aprecia ningún elemento que dé pie al fraude. Es cierto que han pasado dos años desde el traslado de la residencia de la niña a Portugal, tiempo suficiente para que pueda entenderse que en realidad este requisito no sería de mucha utilidad, pues probablemente la entidad no cuente con elementos suficientes para decidir de entrada sobre la situación de la niña y sobre su adoptabilidad.

14. En relación con la exigencia de que sea la entidad pública española competente la que emita el certificado de idoneidad de los adoptantes, si son españoles y residentes en España, como hemos visto, en el caso se aprecian dudas acerca de la efectiva residencia de los promotores de la inscripción. Tanto el Encargado del Registro como la Dirección los presumen domiciliados en España, por haber aportado el certificado de empadronamiento en Vigo, pero se trata de una presunción iuris tantum, otorgando la posibilidad de que demuestren realmente que donde residían cuando la adopción se constituyó era en Portugal, en cuyo caso no sería necesario el certificado español de idoneidad. Sin embargo, como he tratado de demostrar, hay argumentos suficientes para no solicitar más pruebas del domicilio de los promotores, puesto que hay indicios suficientes para entender que en Portugal estaban domiciliados cuando se constituyó la adopción. Tanto aportar el certificado portugués de idoneidad como la propia sentencia avalan este hecho. En ningún momento se habla de que se haya tratado de una adopción transfronteriza, en cuyo caso, debería haberse aplicado el CH 1993 y haberse aportado el correspondiente certificado de haberse constituido conforme al mismo.

${ }^{21}$ Consideran R. Arenas García / C. González Beilfuss, "La Ley de Adopción internacional: entre la realidad y el deseo", Revista Electrónica de Estudios Internacionales, núm. 17, junio, 2009, pp. 27-28, que este requisito puede ser excesivo cuando haya pasado tiempo desde que el niño no reside en España. 